\title{
Basal ice motion and deformation at the ice-sheet margin, West Greenland
}

\author{
David M. CHANDLER, ${ }^{1}$ Richard I. WALLER, ${ }^{2}$ William G. ADAM ${ }^{2}$ \\ ${ }^{1}$ Institute of Geography and Earth Sciences, University of Wales, Aberystwyth SY23 3DB, UK \\ E-mail:dic@aber.ac.uk \\ ${ }^{2}$ School of Earth Sciences and Geography, Keele University, Keele, Staffordshire ST5 5BG, UK
}

\begin{abstract}
Measurements of basal ice deformation at the margin of Russell Glacier, West Greenland, have provided an opportunity to gain more insight into basal processes occurring near the margin. The basal ice layer comprises a debris-rich, heterogeneous stratified facies, overlain by a comparatively debris-poor dispersed facies. Ice velocities were obtained from anchors placed in both ice facies, at three sites under 5-15 $\mathrm{m}$ ice depth. Mean velocities ranged from 20 to $43 \mathrm{~m} \mathrm{a}^{-1}$, and velocity gradients indicate high shear strain rates within the basal ice. Stick-slip motion and diurnal variations were observed during measurements at short (1-5 min) time intervals. Vertical gradients in horizontal ice velocity indicate two modes of deformation: (1) viscous deformation within the stratified ice facies, and (2) shear at the interface between the two basal ice facies. Deformation mode 1 may contribute to the folding and shear structures observed in the stratified facies. Deformation mode 2 may generate the stick-slip motion and be associated with the formation of debris bands. Active deformation close to the margin suggests that structures observed within the basal ice are only partially representative of processes occurring near the bed in areas away from the glacier margin.
\end{abstract}

\section{INTRODUCTION}

Due to the inaccessibility of the glacier bed, basal ice exposures at Arctic glacier margins have been widely studied in order to improve understanding of basal processes (Knight, 1997). Since structures within the basal ice can sometimes be preserved in the sediment record during retreat, knowledge of how observed structures in basal ice relate to processes and dynamics may enable the reconstruction of basal processes from investigations of relict glacial sediments. However, despite significant research, the relationship between basal processes and the development of deformation structures within basal ice layers remains unclear.

This study uses basal motion data collected at the Greenland ice sheet margin to gain further insight into the relationship between basal motion and the generation of specific structures evident within the basal ice layer.

\section{FIELD SITE AND METHODS}

Russell Glacier is an outlet glacier draining the Greenland ice sheet and is located $\sim 20 \mathrm{~km}$ east of Kangerlussuaq (Fig. 1). The glacier margin is characterized by an extensive basal ice layer composed of two main facies: a conspicuously debris-rich stratified facies and an overlying dispersed facies. The stratified facies reaches up to $5 \mathrm{~m}$ in thickness, and contains three distinct subfacies: (1) solid, (2) discontinuous and (3) suspended (see Waller and others, 2000, for details). The dispersed facies comprises a layer up to several tens of metres thick characterized by lenticular clots of silt and clay, and its origin remains uncertain (Sugden and others, 1987; Knight and Knight, 1994). The sequence is also commonly characterized by a series of debris bands emanating from the stratified facies and extending into the dispersed facies. Mean debris concentrations measured by Knight and others (2002) at Russell Glacier were 2\% and $39 \%$ in the dispersed and stratified ice facies respectively.

\section{Measurements of ice deformation}

Fieldwork was carried out at Russell Glacier, West Greenland, (Fig. 1) during August/September 1996 (site 96-1) and September 2002 (sites 02-1 and 02-2). At site 96-1, daily surveys of a vertical array of marker pegs placed in the basal ice (Fig. 2) enabled the construction of a vertical profile of mean horizontal velocity over a 14 day period. Reflectors were attached to each peg, so that their positions could be surveyed by total station to a resolution of approximately $\pm 2 \mathrm{~mm}$ (Waller, 1997).

In 2002, two locations were chosen. Site 02-1 was situated near the terminus of a side lobe of Russell Glacier, where ice was descending an overridden moraine ridge. The thickness of ice above the surface of adjacent moraines was $\sim 5 \mathrm{~m}$, though the true ice thickness may be more than this, and the surface slope was $\sim 10^{\circ}$. Site $02-2$ was located at a second side lobe, under thicker $(15 \mathrm{~m})$ and steeper $\left(15^{\circ}\right)$ ice. Again, the true ice thickness was unclear. Two anchors were placed at each site, one either side of the boundary between the two ice facies. The upper anchor was placed immediately above the boundary; the other $\sim 0.5 \mathrm{~m}$ vertically below. At 02-1, there was a thin layer of loose ice-poor debris within the boundary, but at 02-2 there was direct contact between the two ice facies. A third anchor was fixed in the moraine near the instrument. Anchor positions were measured with drag-spools, using a design similar to those described by Hubbard (2002). Thin copper wire (diameter $\ll 1 \mathrm{~mm}$ ) tied to each anchor was wound onto a multi-turn, conducting-polymer potentiometer fixed to a vertical support. Rotation of the potentiometer was recorded on a data logger every $5 \mathrm{~min}(02-1)$ or $1 \mathrm{~min}(02-2)$. Instrumental resolution is approximately $\pm 0.1 \mathrm{~mm}$. The logger internal temperature was also recorded, and although the temperature was not recorded using standard meteorological equipment, the logger was positioned in permanent shade so that the internal temperature can be used as a qualitative indication of conditions. 


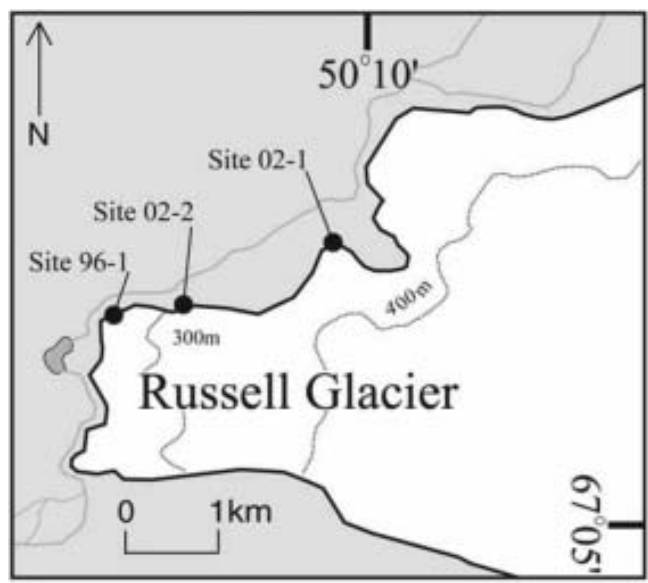

Fig. 1. Map showing the location of Russell Glacier and the sites used during fieldwork in 1996 and 2001.

\section{RESULTS}

A summary of marker positions and velocities at each site is given in Table 1 . The horizontal velocity profile in the vertical array of markers at site 96-1 (Fig. 3) shows a general increase in velocity with height, at a mean shear strain rate of $4.3 \mathrm{a}^{-1}$. There was no measurable difference in the velocity of anchors $\mathrm{U}, \mathrm{M}$ and $\mathrm{L}$. A velocity increase, linked to a rainfall event, occurred during the final 2 days of the 1996 study (Waller and Hart, 1999); these values have been omitted from the mean velocities. A detailed description of the data collected in 1996 can be found in Waller and Hart (1999).

Displacement time series for the anchors in ice at sites 02-1 and 02-2 are shown in Figure 4. The wire attached to the anchor in the stratified facies at 02-1 (anchor P11; Table 1) was disturbed by falling debris; however, measurements of the position of a weighted string suspended between anchors P11 and P12 indicate that the motion of

Table 1. Marker positions and velocities at the three sites. $H$ is approximate ice depth, $v$ is velocity, $\mathrm{SF}$ is stratified facies and DF is dispersed facies. $z$ is the height above the moraine adjacent to the ice, except for site 96-1 where $z$ is the height above marker 6

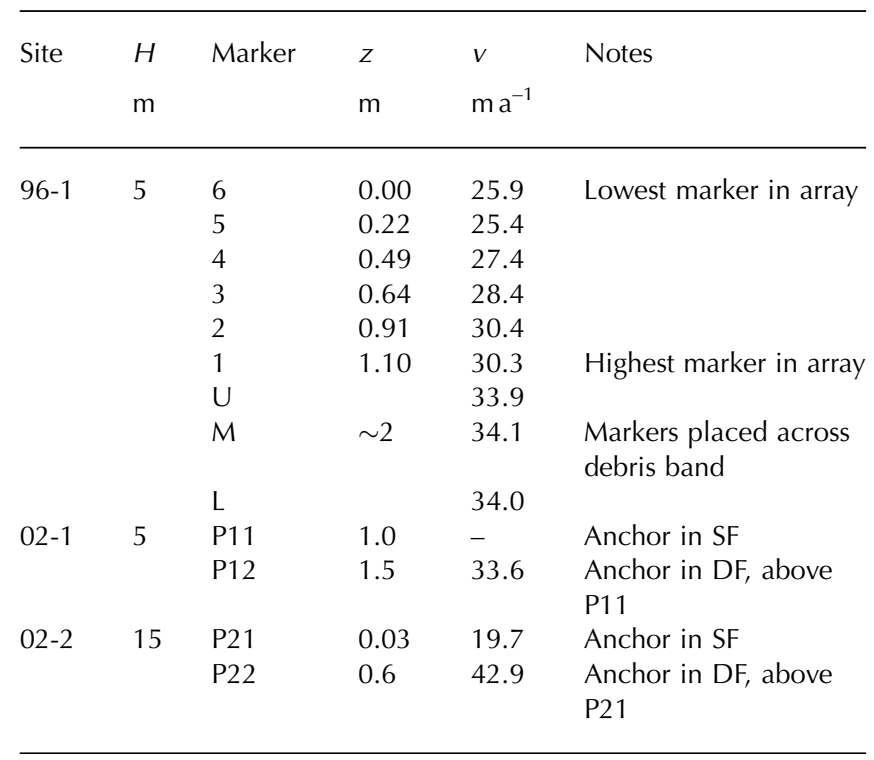



Fig. 2. Configuration of marker pegs at site 96-1. Pegs 1-6 were in the basal ice layer (BIL), and pegs $U, M$ and L across a debris band in the englacial ice. The pronounced surface topography is probably due to surface ablation.

$\mathrm{P} 11$ was small $\left(<5 \mathrm{~mm} \mathrm{~d}^{-1}\right)$ in comparison with $\mathrm{P} 12$. This is in contrast to site 02-2, where P22 moved at about half the speed of P21. At both sites, anchors placed in moraine adjacent to the instrument recorded negligible motion, with the wire remaining taut, which confirms that the support remained well fixed during the measurement period.

Anchor P12 shows long periods of zero motion, with most of the displacement occurring during the afternoon. This coincides with warmer air temperatures. Diurnal variations were not present at site 02-2, but the temperature range was much smaller (Fig. 4d). Motion of P21 (the lower anchor) appears to be smooth over hourly timescales (Fig. 4b), and stick-slip at sub-hourly timescales (Fig. 5). P22 (the upper anchor) moved more steadily, but some of the larger slip events in P21 were seen in both anchors. The difference in mean velocity of P21 and P22 indicates a shear strain rate of approximately $40 \mathrm{a}^{-1}$ over the distance of $\sim 0.6 \mathrm{~m}$ between the anchors.

\section{DISCUSSION}

The motion data from all three sites clearly show that deformation is occurring within the basal ice layer. The velocity profile at site 96-1 (Fig. 3) shows that this deformation occurs throughout the vertical array of pegs in the basal ice, although there was no measurable shear across the

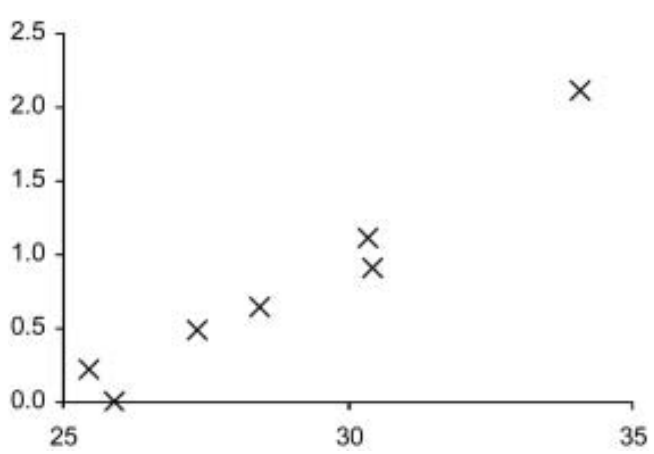

Fig. 3. Velocity profile for site 96-1. $z$ is the height above the bottom marker (peg 6). 


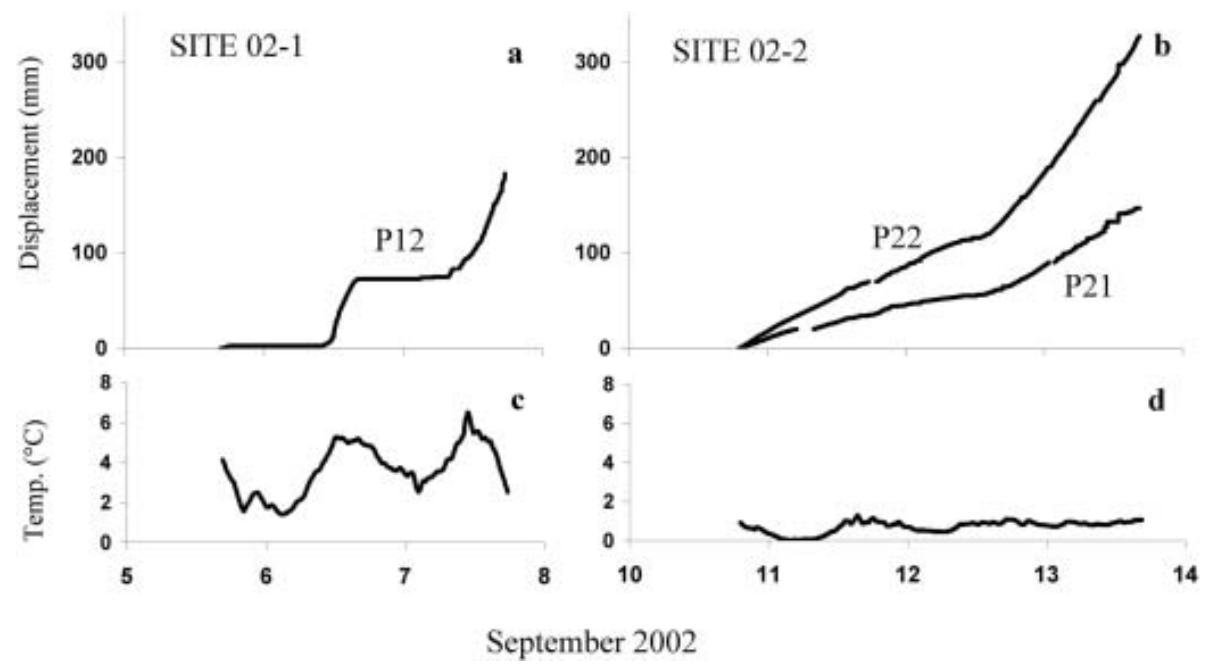

Fig. 4. Anchor displacement (a, b) and logger internal temperature (c, d) at sites 02-1 and 02-2.

debris band. This is in contrast to Waller and Hart (1999) who concluded that very little deformation was occurring in the basal ice. This difference can be attributed to the use of the mean velocity here, rather than the widely scattered individual daily readings (as in Waller and Hart, 1999), which makes the overall vertical velocity gradient much clearer. Small reversals in the gradient between pegs 1 and 2 , and between pegs 5 and 6 , are probably instrumental, reflecting difficulties in keeping pegs secured in the ice.

Vertical variations in mean horizontal velocity indicate high shear strain rates in the stratified facies: approximately $4.3 \mathrm{a}^{-1}$ (site 96-1) and $40.7 \mathrm{a}^{-1}$ (site 02-2) (Table 2). Such high values, which occur under relatively shallow ice, may result from a high effective stress due to strong longitudinal compression. Alternatively, the high debris concentrations in the stratified facies, or individual weak layers (in particular, the boundary between the two facies), may soften the ice. This is consistent with previous studies of basal ice softness (e.g. in Greenland (Thorsteinsson and others, 1999) and Norway (Cohen, 2000 and references therein)).

Given the broken nature of the boundary between the two facies at site 02-1, it is likely that most or all of the motion of P12 can be attributed to shear within the contact.

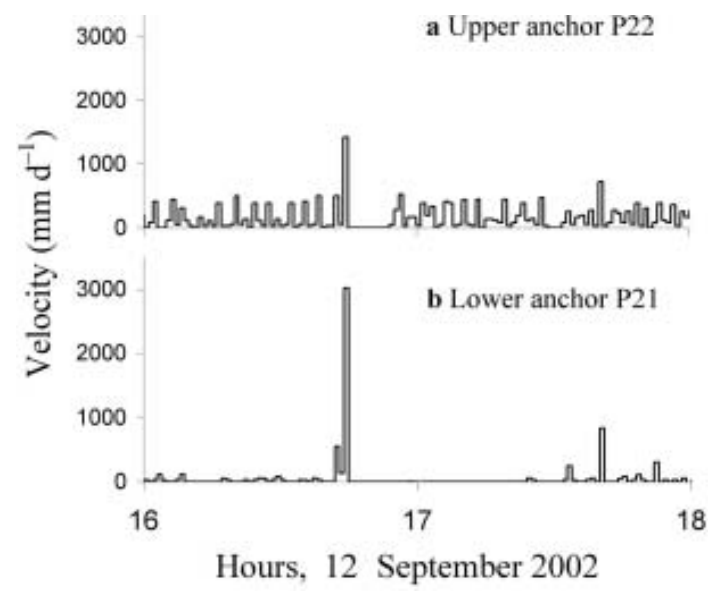

Fig. 5. A typical 2 hour section of the velocity time series for site 02-2, showing stick-slip motion.
Therefore two modes of deformation were observed to occur at the margin: viscous deformation within the stratified facies, which may be responsible for the intense folding in this layer; and brittle deformation, that may be associated with the formation of the debris bands.

Increases in ice velocity during warmer temperatures (site 02-1; Fig. 4) and after rain (Waller and Hart, 1999) suggest that water inputs to the glacier are a control on the dynamics, as reported at many other glaciers; however, in this case the variations are found at the margin. It is uncertain whether the hydrological controls operate up-glacier and are transferred to the margin via longitudinal stresses, or whether these variations are a local effect. Since no moulins were observed within a 50-100 m distance up-glacier, it seems that stress transfer would be the most likely cause. The reason for the increase in velocity at site $02-2$ during 12 September remains unclear, but we speculate that it is also linked to changes in meteorological conditions, which we were unable to detect without a meteorological station. If hydrological controls are the source of these variations, there must be warm-based regions up-glacier from the margin, which is in agreement with previous isotopic studies concerning basal ice formation (Knight, 1997).

Stick-slip motion, seen at site 02-2 (Fig. 5), has been observed in basal sliding data elsewhere (e.g. Fischer and Clarke, 1997; Hubbard, 2002). Here, the distribution of slip sizes for anchor P21 (Fig. 6) fits a power-law relationship in which the probability of a slip being greater than a length $x$ is proportional to $x^{-1.3}$. The existence of similar power-law distributions has been reported from a wide range of natural phenomena (Turcotte, 1999), including friction-controlled

Table 2. Measured shear strain rates $\epsilon_{x z}$ and estimated parameters ice depth $H$ and surface slope $\theta$

\begin{tabular}{llll}
\hline Site & $H$ & $\theta$ & $\epsilon_{x z}$ \\
& $\mathrm{~m}$ & $\circ$ & $\mathrm{a}^{-1}$ \\
\hline $96-1$ & 5 & & \\
$02-2$ & 15 & 10 & 4.3 \\
& & 15 & 40.7 \\
\hline
\end{tabular}




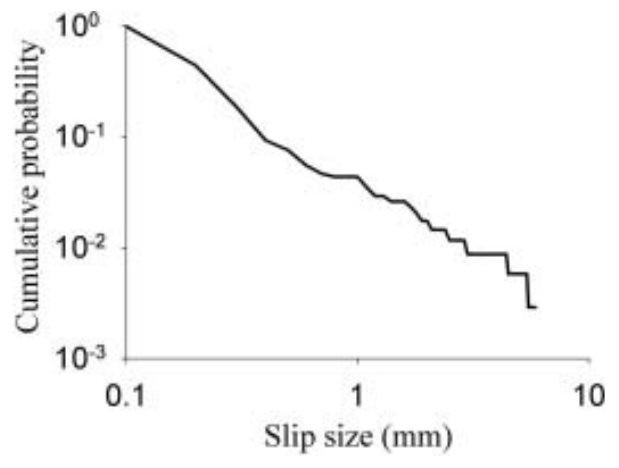

Fig. 6. Distribution of slip sizes for anchor P21. The cumulative probability fits a power-law relationship.

systems such as earthquakes. In a glacier, stick-slip can arise from cycles of elastic strain build-up and release, due to rock-rock friction in a layer of direct slip. Such a layer might be the bed or an internal shear plane. Smooth basal motion has been found during more recent use of the same instrument in the Alps (Chandler and others, unpublished information), so we are confident that the results here are not instrumental artifacts.

\section{CONCLUSIONS}

Measurements of the motion and deformation of basal ice at three locations at the margin of Russell Glacier allow a number of conclusions to be drawn:

1. High rates of shear were recorded in the basal ice at two out of three sites studied.

2. Input of surface water up-glacier has an impact on glacier dynamics near the margin, suggesting efficient long-stress transfer and a warm-based regime away from the margin.

3. Stick-slip motion indicates sliding at the bed or shearing within discrete layers of debris-rich ice.

4. Basal ice near the margin is actively deforming. This occurs via both viscous and brittle deformation.

5. The structures observed in basal ice sequences are unlikely to represent conditions under deeper ice upglacier.

\section{ACKNOWLEDGEMENTS}

Financial support was received from Southampton University and Keele University, and the Quaternary Research Association funded field visits by R.I.W. in 1996 and 2002. D.M.C. was partly funded by UK Natural Environment Research Council studentship NER/S/A/2001/06374. W.G.A. received financial support from the Quaternary Research Association and the Carnegie Trust for the Universities of Scotland. B. Hubbard provided equipment for the 2002 field visit, and a research permit was provided by the Danish Polar Centre. The paper has benefited from comments by R.LeB. Hooke, an anonymous referee and the scientific editor (N. Reeh).

\section{REFERENCES}

Cohen, D. 2000. Rheology of ice at the bed of Engabreen, Norway. J. Glaciol., 46(155), 611-621.

Fischer, U.H. and G.K.C. Clarke. 1997. Stick-slip sliding behaviour at the base of a glacier. Ann. Glaciol., 24, 390-396.

Hubbard, B. 2002. Direct measurement of basal motion at a hardbedded, temperate glacier: Glacier de Transfleuron, Switzerland. J. Glaciol., 48(160), 1-8.

Knight, P.G. 1997. The basal ice layer of glaciers and ice sheets. Quat. Sci. Rev., 16(9), 975-993.

Knight, P.G. and D.A. Knight. 1994. Correspondence. Glacier sliding, regelation water flow and development of basal ice. J. Glaciol., 40(136), 600-601.

Knight, P.G., R.I. Waller, C.J. Patterson, A.P. Jones and Z.P. Robinson. 2002. Discharge of debris from ice at the margin of the Greenland ice sheet. J. Glaciol., 48(161), 192-198.

Paterson, W.S.B. 1994. The physics of glaciers. Third edition. Oxford, etc., Elsevier.

Sugden, D.E. and 6 others. 1987. Evidence for two zones of debris entrainment beneath the Greenland ice sheet. Nature, 328(6127), 238-241.

Thorsteinsson, T., E.D. Waddington, K.C. Taylor, R.B. Alley and D.D. Blankenship. 1999. Strain-rate enhancement at Dye 3, Greenland. J. Glaciol., 45(150), 338-345.

Turcotte, D.L. 1999. Self-organized criticality. Rep. Prog. Phys., 62(10), 1377-1429.

Waller, R.I. 1997. The role of tectonism in the distribution, appearance and dynamic behaviour of debris-rich basal ice. (PhD thesis, University of Southampton.)

Waller, R.I. and J.K. Hart. 1999. Mechanisms and patterns of motion associated with the basal zone of the Russell Glacier, south-west Greenland. J. Glacial Geol. Geomorph., 21, 1-20.

Waller, R.I., J.K. Hart and P.G. Knight. 2000. The influence of tectonic deformation on facies variability in stratified debris-rich basal ice. Quat. Sci. Rev., 19(8), 775-786. 